\section{Systemic Lupus Erythematosus Disease Activity Index 2000 Responder Index-50 Website}

\section{To the Editor:}

We read with great interest the editorial ${ }^{1}$ by David A. Isenberg related to our article, "Development and Assessment of Users' Satisfaction with the Systemic Lupus Erythematosus Disease Activity Index 2000 Responder Index-50 Website"2 (S2K RI-50).

Dr. Isenberg states that a drawback of the S2K RI-50 is that it does not identify patients whose clinical features are worse. However, outcome measures in clinical trials in systemic lupus erythematosus (SLE) measure improvement from baseline, or flares over the course of the study from baseline. Both of these are well identified by Systemic Lupus Erythematosus Disease Activity Index (SLEDAI-2K) and S2K RI-50. Flares can certainly be ascertained by SLEDAI criteria (increase by 4 or more) $)^{3}$ and the S2K RI-50 identified an improvement that is less than complete resolution ${ }^{4}$. Thus the index has the necessary features to be a primary outcome measure in SLE drug trials. Unlike BILAG, it is simple, intuitive, and gives actual metrics for improvement, not lettered categories such as A, B, C, etc.

The S2K RI-50 Website, www.s2k-ri-50.com, is currently being used to prepare clinicians to use the S2K RI-50 in clinical trials and research settings ${ }^{2}$.

ZAHI TOUMA, MD, FACP, PhD, University of Toronto Lupus Clinic, Toronto Western Hospital, Centre for Prognosis Studies in the Rheumatic Diseases; MURRAY B. UROWITZ, MD, FRCPC, Professor of Medicine, University of Toronto, Senior Scientist, Toronto Western Research
Institute, Director, University of Toronto Lupus Clinic, Centre for Prognosis Studies in the Rheumatic Diseases, Toronto Western Hospital; DAFNA D. GLADMAN, MD, FRCPC, Professor of Medicine, University of Toronto, Senior Scientist, Toronto Western Research Institute, Co-Director, University of Toronto Lupus Clinic, Centre for Prognosis Studies in the Rheumatic Diseases, Toronto Western Hospital, University of Toronto, Toronto, Ontario, Canada. Address correspondence to Dr. M.B. Urowitz, Centre for Prognosis Studies in the Rheumatic Diseases, Toronto Western Hospital, Room 1E-409, 399 Bathurst Street, Toronto, Ontario M5T 2S8, Canada. E-mail: m.urowitz@utoronto.ca

\section{REFERENCES}

1. Isenberg DA. Rhubarb and reliability - A Jane Austen view of systemic lupus erythematosus [editorial]. J Rheumatol 2013;40:7-8.

2. Touma Z, Gladman DD, MacKinnon A, Carette S, Abu-Shakra M, Askanase A, et al. Development and assessment of users' satisfaction with the Systemic Lupus Erythematosus Disease Activity Index 2000 Responder Index-50 Website. J Rheumatol 2013;40:34-9.

3. Gladman DD, Urowitz MB, Kagal A, Hallett D. Accurately describing changes in disease activity in systemic lupus erythematosus. J Rheumatol 2000;27:377-9.

4. Touma Z, Gladman DD, Ibanez D, Urowitz MB. Development and initial validation of the Systemic Lupus Erythematosus Disease Activity Index 2000 Responder Index 50. J Rheumatol 2011;38:275-84.

J Rheumatol 2013;40:5; doi:10.3899/jrheum.130030 